
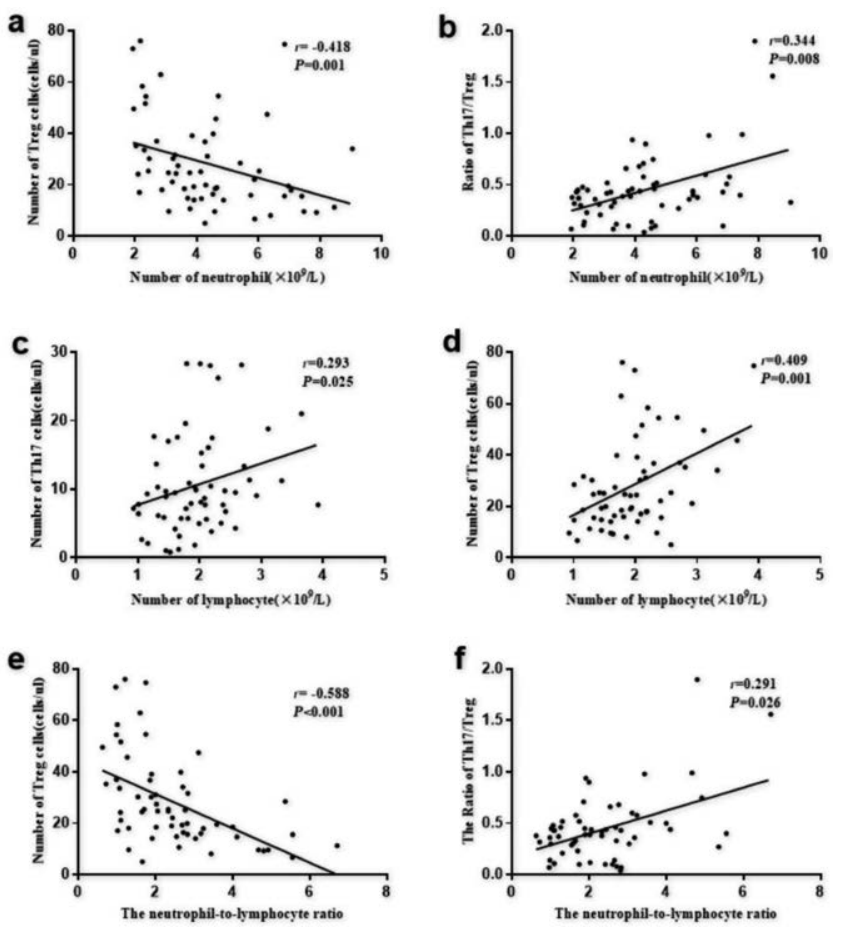

Figure 2. Correlation coefficient and regression line of the number of Th17 cells, the number of Treg cells, Th17/Treg with the the number of neutrophil, the number of lymphocyte, the NLR were represented as scatter plots.

Disclosure of Interests: None declared

DOI: 10.1136/annrheumdis-2020-eular.1411

\section{FRI0209 EFFECTS OF ADD-ON METHOTREXATE IN POLYMYALGIA RHEUMATICA PATIENTS: A RETROSPECTIVE STUDY}

D. Marsman ${ }^{1}$, T. Bolhuis ${ }^{1}$, N. Den Broeder ${ }^{1}$, F. Van den Hoogen ${ }^{1}$, A. Den Broeder ${ }^{1}$, A. Van der Maas ${ }^{1} .{ }^{1}$ Sint Maartenskliniek, Nijmegen, Netherlands

Background: Guidelines on polymyalgia rheumatica (PMR) recommend early introduction of methotrexate (MTX), especially in patients with worse prognosis such as flare or glucocorticoid (GC)-related adverse events (AE). ${ }^{1}$ GC-AE are reported in up to $65 \%$ of PMR patients, ${ }^{2}$ and $50 \%$ of secondary care patients are unable to discontinue GCs, emphasizing the need for GC-sparing agents. ${ }^{3}$ However, evidence regarding MTX efficacy in PMR remains limited. ${ }^{2}$

Objectives: To assess the efficacy of add-on MTX in preventing subsequent flares and GC- sparing in PMR patients.

Methods: In a retrospective cohort of newly diagnosed PMR patients visiting our hospital from April 2008 - January 2018, patients starting methotrexate (index event) were compared to first-time flaring PMR patients in whom MTX was not started (control group). Concomitant inflammatory rheumatic diseases were excluded. Data on patient, disease and treatment characteristics were compared. Main outcomes were difference in number of subsequent flares per year between groups (multivariable Poisson regression) and mean GC-use (total GC-dose/total follow-up; multivariable linear regression). In the MTX group only, also incidence rate ratio of flare before vs. after starting MTX was assessed.

Results: Of 454 PMR patients, 262 were selected; 42 receiving MTX and 220 in the control group. Reasons for prescribing MTX were GC ineffectiveness and/or GC-related AE and MTX starting dose was 10,15 and $25 \mathrm{mg} /$ week in 11 $\%, 82 \%$ and $2 \%$ respectively. Adjusted for covariates, mean GC-use was 1.21 higher in the MTX group compared to the control group $(p=0.155)$. The yearly incidence rate of flares in the MTX group did not differ from the control group: incidence rate ratio (IRR) $0.93,(95 \% \mathrm{Cl} 0.53-1.63)$. The yearly flare rate was 1.19 before and 0.42 after MTX initiation, resulting in an IRR of $0.36(95 \% \mathrm{Cl}$ 0.24-0.53)

Conclusion: MTX is infrequently prescribed in daily clinical practice, despite guideline recommendations. No difference in GC use or flare incidence was seen between MTX treated patients and controls, although within MTX treated patients, flare rates were lower after MTX start. Confounding by indication may explain the lack of difference in the outcomes between groups. The optimal timing and dosage of MTX in PMR remains unclear, justifying a clinical trial.

\section{References:}

[1] Dejaco C. e.al. 2015. Recommendations. management.of.polymyalgia rheumatica:a.European.League.Against Rheumatism/American.College. of.Rheumatology.collaborative.initiative.ARD.2015;74:1799-1807.

[2] L.Couvaras.etal.Prevalence.of.Iong-term.steroid.therapy:French data. AB1141 (2017)

[3] González-Gay MA et al. Polymyalgia. rheumatica. Lancet. 2017 Oct 7;390(10103):1700-1712

Table 1. Patients characteristics methotrexate versus controls

\begin{tabular}{|c|c|c|c|c|}
\hline & $\begin{array}{l}\text { MTX } \\
\mathrm{N}=42\end{array}$ & $\begin{array}{l}\text { Controls } \\
\mathrm{N}=220\end{array}$ & P-value & $\begin{array}{l}\text { Difference } \\
(95 \% \mathrm{Cl})\end{array}$ \\
\hline \multicolumn{5}{|l|}{ Time of PMR diagnosis } \\
\hline Female(\%) & $22(52)$ & $127(58)$ & 0.611 & $-5.3(-11.0 ; 21.7)$ \\
\hline Age,years*(SD) & $62(7)$ & $67(10)$ & 0.002 & $-5.0(-8.2 ;-1.8)$ \\
\hline Previous history PMR(\%) & $7(17)$ & $13(6)$ & 0.025 & $10.8(2.0 ; 19.5)$ \\
\hline PMR symptoms, weeks(IQR) & $9(6-16)$ & $5(5-16)$ & 0.639 & \\
\hline Bilateral shoulderpain(\%) & $42(100)$ & 209(95) & 0.221 & $5.0(-1.6 ; 11.6)$ \\
\hline $\begin{array}{l}\text { Morning stiffness }>45 \text { minutes }(\% ; n=33 \\
\text { versus } 159)\end{array}$ & $32(76)$ & $177(80)$ & 0.533 & $-4.3(-17.5 ; 9.0)$ \\
\hline $\begin{array}{l}\text { Elevated ESR/CRP }{ }^{*},(\% ; n=41 \text { versus } \\
\text { 218) }\end{array}$ & \multicolumn{3}{|c|}{ 218) } & $12.7(1.4 ; 24.0)$ \\
\hline \multicolumn{5}{|l|}{ At index event } \\
\hline PMR duration, weeks ${ }^{\star, \star \star}($ IQR) & $87(41-116)$ & $53(33-80)$ & 0.001 & \\
\hline GC-dose index event & $39(93)$ & & & \\
\hline Oral & $10(5-15)$ & $210(95)$ & & \\
\hline $\mathrm{Mg}(\mathrm{IQR})^{\star}$ & $3(7)$ & $5(0-8)$ & 0.000 & \\
\hline Intramuscular(\%) & $120(100-$ & $10(5)$ & & \\
\hline $\mathrm{Mg}(\mathrm{IQR})$ & 120) & $100(80-120)$ & 0.355 & \\
\hline $\begin{array}{l}\text { Mean GC-dose until index event, mg, } \\
(\text { IQR; } n=33 \text { versus } 170)^{*}\end{array}$ & $7.1(5.9-9.0)$ & $5.7(3.8-7.4)$ & 0.000 & \\
\hline \multicolumn{5}{|l|}{ During follow-up } \\
\hline Flares, $n(\%)$ & $21(50)$ & $100(45)$ & 0.616 & $4.5(-21.0 ; 11.9)$ \\
\hline Weeks to first flare (IQR) & $36(24-51)$ & $39(22-66)$ & 0.517 & \\
\hline Mean GC-dose, mg (IQR) & $6.2(4.6-9.7)$ & $4.7(2.9-6.9)$ & 0.004 & \\
\hline $\begin{array}{l}\text { Daily GC-dose year1,mg (IQR; } n=32 \\
\text { versus } 153)^{*}\end{array}$ & 5 (2.5-7.9) & $2.5(0-5)$ & 0.03 & \\
\hline
\end{tabular}

* Significant alpha level $<0.05$

${ }^{*}$ Before diagnosis until index event

Disclosure of Interests: None declared

DOI: 10.1136/annrheumdis-2020-eular.2986

FRI0210

ORBITAL PSEUDOTUMOR AMONG PATIENTS WITH GRANULOMATOSIS WITH POLYANGIITIS - DATA FROM THE POLISH REGISTRY POLVAS

A. Masiak ${ }^{1}$, M. Ziętkiewicz ${ }^{1}$, K. Wójcik ${ }^{2}$, K. Wawrzycka-

Adamczyk $^{2}$, R. Jeleniewicz ${ }^{3}$, M. Madej ${ }^{4}$, J. Kur-Zalewska ${ }^{5}$, K. Jakuszko $^{6}$

M. Wisłowska ${ }^{7}$, H. Storoniak ${ }^{8}$, M. Komorniczak ${ }^{8}$, B. Bułło-Piontecka ${ }^{8}$,

I. Brzosko ${ }^{9}$, M. Stasiek ${ }^{10}$, E. Kucharz ${ }^{11}$, A. Dębska-Ślizień ${ }^{8}$, M. Majdan ${ }^{3}$,

J. Musiat ${ }^{2}, Z$. Zdrojewski ${ }^{1}{ }^{1}$ Medical University of Gdańsk, Department of

Internal Medicine, Connective Tissue Diseases and Geriatrics, Gdańsk, Poland;

${ }^{2}$ Jagiellonian University Medical College, 2nd Department of Internal Medicine,

Faculty of Medicine, Krakow, Poland; ${ }^{3}$ Medical University of Lublin, Department of Rheumatology and Connective Tissue Diseases, Lublin, Poland; ${ }^{4}$ Medical University, Wrocław, Department of Rheumatology and Internal Medicine, Wroclaw, Poland; ${ }^{5}$ Military Medicine Institute, Department of Internal Medicine and Rheumatology, Warsaw, Poland; ${ }^{6}$ Medical University, Wroctaw, Department of Nephrology and Transplantation Medicine, Wroctaw, Poland; ${ }^{7}$ Central Clinical Hospital of the Ministry of the Interior and Administration, Department of Internal Diseases and Rheumatology, Warsaw, Poland; ${ }^{8}$ Medical University of Gdańsk, Department of Nephrology, Transplantology and Internal Diseases, Gdańsk, Poland; ${ }^{9}$ Pomeranian Medical University in Szczecin, Department of Rheumatology, Internal Diseases, Geriatrics and Clinical Immunology, Szczecin Poland: ${ }^{10}$ National Institute of Geriatrics, Rheumatology and Rehabilitation, Department of Rheumatology, Warsaw, Poland; ${ }^{11}$ Medical University of Silesia, Department of Internal Medicine, Rheumatology and Clinical Immunology, Katowice, Poland

Background: Orbital inflammatory masses have been described as the common manifestation of granulomatosis with polyangiitis (GPA) occuring in $7-45 \%$ of patients.

Objectives: Identification and characterization of patients with orbital pseudotumor among Polish patients based on the national vasculitis registry, POLVAS.

Methods: Clinical presentation and management of all GPA patients fulfilling ACR criteria or Chapel Hill Consensus Conference definition included to the Polish registry POLVAS who developed orbital masses in the course of GPA were evaluated. 
Results: Ocular involvement was found in 114 (27\%) of 417 GPA patients registered in POLVAS, 34 (8\%) developed orbital masses. Mean patients' age was 47.8 (range from 19-75) yrs., 23 (67\%) were women. Forty four per cent of the patients developed tumor at the beginning of the disease, $56 \%$ during relapse. Patients' characteristics on diagnosis of orbital mass: 24 cANCA, 2 pANCA, and 8 ANCA negative, $9 \%$ active smokers and $31 \%$ past smokers, $29 \%$ had localized disease, $21 \%$ early systemic and $50 \%$ systemic with organ involvement, $29 \%$ had other type of ophthalmological involvement before pseudotumor occurred, $88 \%$ had active paranasal sinus involvement, $41 \%$ lungs, $15 \%$ CNS, $15 \%$ skin and $6 \%$ heart manifestations. Thirty seven per cent of patients had positive nasal swabs cultures, $50 \%$ of which were positive for Staphylococcus aureus. In $65 \%$, tumor occurred during steroid therapy ( $46 \%$ had prednisone more than $5 \mathrm{mg} / \mathrm{d}$ ) and $45 \%$ on immunosuppressive treatment (19\% when treated with AZA, $16 \%$ MTX, 6,5\% MMF and 3,5\% CYC). Due to orbital mass $86.5 \%$ were treated with CYC and $13.5 \%$ with RTX. Twenty one per cent had complete remission of the pseudotumor, $76 \%$ partial remission and in $3 \%$ patients there was no response to the treatment; $43 \%$ developed visual impairment, $20 \%$ suffered from blindness. Conclusion: Orbital inflammatory mass was not common manifestation of GPA among our patients. The mass developed at the beginning or in the course of the disease, even during immunosuppressive treatment. Orbital masses have been resistant to therapeutic interventions and were accompanied by high risk of visual impairment.

Disclosure of Interests: Anna Masiak: None declared, Marcin Ziętkiewicz: None declared, Krzysztof Wójcik: None declared, Katarzyna Wawrzycka-Adamczyk: None declared, Radoslaw Jeleniewicz: None declared, Marta Madej: None declared, Joanna Kur-Zalewska: None declared, Katarzyna Jakuszko: None declared, Małgorzata Wisłowska: None declared, Hanna Storoniak: None declared, Michał Komorniczak: None declared, Barbara Bułło-Piontecka: None declared, Iwona Brzosko: None declared, Małgorzata Stasiek: None declared, Eugeniusz Kucharz: None declared, Alicja Dębska-Ślizień: None declared, Maria Majdan Consultant of: Roche, Amgen, Speakers bureau: Roche, Amgen, Jacek Musiał: None declared, Zbigniew Zdrojewski: None declared DOI: 10.1136/annrheumdis-2020-eular.2881

\section{FRI0211 VASCULITIS ASSOCIATED WITH MYELODYSPLASTIC SYNDROME AND CHRONIC MYELOMONOCYTIC LEUKEMIA: FRENCH MULTICENTER CASE CONTROL STUDY}

A. Roupie ${ }^{1}$, B. Terrier ${ }^{2}$, P. Fenaux ${ }^{1}$, O. Fain ${ }^{1}$, A. Mekinian ${ }^{1}$ on behalf of Minhemon. ' Sorbonne University, Internal Medicine Department, Saint Antoine Hospital, Paris, France, ${ }^{2}$ Paris Descartes V University, Internal Medicine Department, Saint Antoine Hospital, Paris, France

Background: Myelodysplastic syndromes (MDS) and MDS/myeloproliferative neoplasms (MDS/MPN) can be associated with vasculitis.

Objectives: In this nationwide study by the "French Network of dysimmune disorders associated with hemopathies" (MINHEMON) the objective was to evaluate characteristics, treatment and outcome of vasculitis MDS-MDS/MPN.

Methods: Retrospective analysis of patients that presented a MDS/MPN associated with vasculitis and compared the overall survival and acute leukemia with MDS without vasculitis.

Results: Seventy patients with vasculitis and MDS/MPN were included, with a median age of 71.5 [21-90] years and male/female ratio of 2.3. Vasculitis was diagnosed prior to MDS/MPN in 31 patients (44.3\%), with a median time of 27 months [1-120] between two diagnosis, and after in 20 patients ( 6 months [1-59]). In comparison to $183 \mathrm{MDS} / \mathrm{MPN}$ without dysimmune features showed no difference in MDS/MPN subtypes distribution nor median IPSS/CPSS scores in patients with and without vasculitis. The vasculitis subtypes was giant-cell arteritis (GCA) in 24 patients $(34 \%)$. Eleven patients $(20 \%)$ had Behçet's-like syndrome and 6 patients $(9 \%)$ presented with polyarteritis nodosa. Steroids $(60 \mathrm{mg} /$ day [0-500] of prednisone equivalent) were used as first-line therapy for MDS/MPN vasculitis in 64/70 patients (91\%) and 41 (59\%) received combined immunosuppressive therapies during the follow-up. After the follow-up of 33.2 months [1-162], 31 patients (44\%) finally experienced sustained remission. At least one relapse during the 33.2 months [1-162] follow-up occurred in 43 patients $(61 \%)$. Relapse rates were higher in patients treated by DMARDs (odds ratio at 4.86 [95\% Cl $1.38-17.10]$ ), but did not differ from biologics (odds ratio 0.59 [95\% $\mathrm{Cl} 0.11-3.20]$ ) and azacytidine (odds ratio 1.44 [95\% $\mathrm{Cl} 0.21-9.76]$ ) (steroids considered as reference). Overall survival and progression to acute myeloid leukemia in MDS/MPN vasculitis were not significantly different from MDS/MPN patients without any dysimmune features $(p=0.5)$.

Conclusion: This first largest study of MDS/MPN vasculitis show no correlation of vasculitis subtypes with various subtypes and severity of MDS/MPN, and no significant impact of vasculitis on overall survival and progression to acute myeloid leukemia. The high relapse rats and steroid dependence raise the question of combined therapies to steroids. Whereas DMARDs use seem to be avoid specific azacytidine therapy could be considered for even low-risk MDS/MPN vasculitis.
Acknowledgments: minhemon gfm gfev Disclosure of Interests: None declared DOI: 10.1136/annrheumdis-2020-eular.4485

\section{FRI0212 \\ THE ROLE OF AGE ON THE CLINICAL PRESENTATION AND RELAPSE RATES IN A LARGE COHORT OF 720 PATIENTS WITH GIANT CELL ARTERITIS}

S. Monti ${ }^{1}$, L. Dagna ${ }^{2}$, C. Campochiaro ${ }^{2}$, A. Tomelleri ${ }^{2}$, G. Zanframundo ${ }^{1}$, C. Klersy ${ }^{3}$, F. Muratore ${ }^{4}$, L. Boiardi' ${ }^{4}$, R. Padoan ${ }^{5}$, M. Felicetti ${ }^{5}$, F. Schiavon 6 , M. Bond ${ }^{7}$, A. Berti ${ }^{7}$, R. Bortolotti ${ }^{7}$, C. Nannini ${ }^{8}$, F. Cantini $i^{8}$, A. Giollo ${ }^{9}$, E. Conticini ${ }^{10}$, A. Gattamelata ${ }^{11}$, R. Priori ${ }^{11}$, L. Quartuccio $^{12}$, E. Treppo ${ }^{12}$, G. Emmi ${ }^{13}$, M. Finocchi ${ }^{13}$, G. Cassone ${ }^{14}$, A. Hoxha ${ }^{15}$, R. Foti ${ }^{16}$, M. Colaci ${ }^{16}$, R. Caporali ${ }^{17}$, C. Salvarani ${ }^{18}$, C. Montecucco ${ }^{1}$ on behalf of Italian Society of Rheumatology Vasculitis Study Group. ${ }^{1}$ Pavia, Rheumatology, IRCCS Fondazione Policlinico S. Matteo, Pavia, Italy; ${ }^{2}$ Milan, Immunology, VitaSalute San Raffaele University, Milan, Italy; ${ }^{3}$ Pavia, Biometry and Clinical Epidemiology, IRCCS Fondazione Policlinico S. Matteo, Pavia, Italy; ${ }^{4}$ Reggio Emilia, Rheumatology Unit, AUSL-IRCCS di Reggio Emilia, Reggio Emilia, Italy; ${ }^{5}$ Padova, Rheumatology, Padua, Italy; ${ }^{6}$ Padua, Rheumatology, Padua, Italy; ${ }^{7}$ Trento, Rheumatology, Trento, Italy; ${ }^{8}$ Prato, Rheumatology, Prato, Italy ${ }^{9}$ Verona, Rheumatology, Verona, Italy; ${ }^{10}$ Siena, Rheumatology, Siena, Italy;

${ }^{11}$ Rome, Policlinico Umberto I, Rome, Italy; ${ }^{12}$ Udine, Rheumatology, Udine, Italy; ${ }^{13}$ Florence, Immunology, Florence, Italy; ${ }^{14}$ Modena, Rheumatology, Modena, Italy; ${ }^{15}$ Vicenza, Ospedale San Bortolo, Vicenza, Italy; ${ }^{16}$ Catania, Rheumatology, Catania, Italy; ${ }^{17}$ Milan, Rheumatology, Ist. Pini, Milan, Italy; ${ }^{18}$ Reggio Emilia, Rheumatology Unit, AUSL-IRCCS di Reggio Emilia, University of Modena and Reggio Emilia, Reggio Emilia, Italy

Background: Giant cell arteritis (GCA) is the most frequent systemic vasculitis after the age of 50 years old. Recent interest in the processes of immune and vascular aging have been proposed as a disease risk factor. Data on the impact of age at diagnosis of GCA on the clinical course of the disease are scarce Objectives: To assess the role of age at diagnosis of GCA on the risk and time to relapse

Methods: Centres participating in the Italian Society of Rheumatology Vasculitis Study Group retrospectively enrolled patients with a diagnosis of GCA until December 2019. The cohort was divided in tertiles according to age at diagnosis ( $\leq 72 ; 73-79 ;>79$ years old). Negative binomial regression was used to assess the relapse rate according to age groups, and Cox regression for time to first relapse.

Results: Of 720 patients enrolled in 14 Italian reference centres, 711 had complete follow-up data (female $50 \%$; mean age $75 \pm 7$ ). Median follow-up duration was 34 months (IQR 16;70). Patients in the older group at diagnosis (> 79 years) had more frequent visual loss compared to the $73-79$ and $\leq 72$ age groups $(31 \%$ vs $20 \%$ vs $7 \%$; $p<0.001)$, but lower rates of general symptoms ( $56 \%$ vs $70 \%$ vs $77 \%$; $p<0.001$ ). Large-vessel (LV)-GCA was less frequent in the older group ( $18 \%$ vs $22 \%$ vs $43 \%$; $p<0.001$ ). At least one relapse occurred in $47 \%$ of patients. Median time to relapse was 12 months (IQR 6;23). Age did not influence the rate of relapses [18 per 100 persons/years $(95 \% \mathrm{Cl} 15 ; 21)$ vs $19(95 \% \mathrm{Cl} 17 ; 22)$ vs 19 $(95 \% \mathrm{Cl} 17 ; 22)]$, nor the time to first relapse (Figure 1). LV-GCA, presentation with significantly elevated c-reactive protein (>50 mg/L) and general symptoms were independent predictors of relapse.

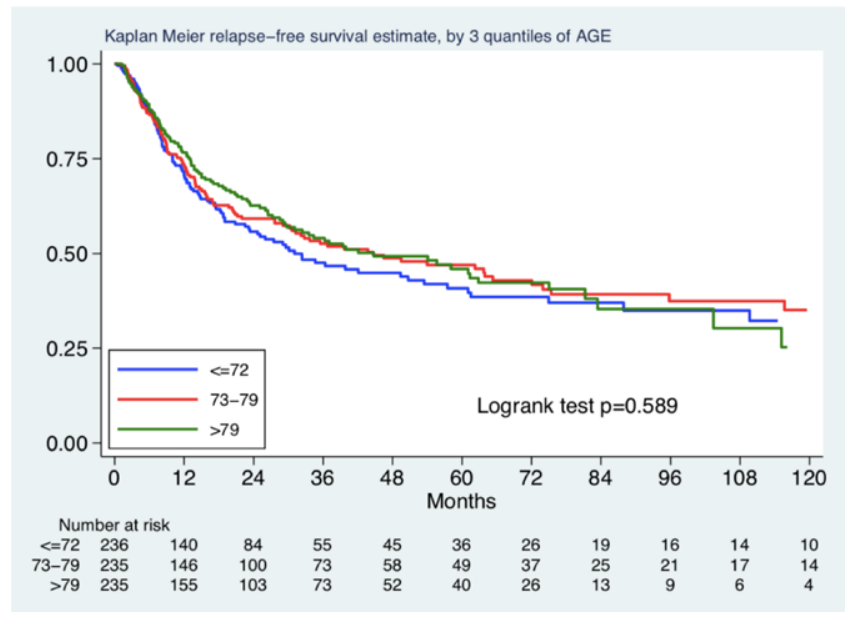

Conclusion: Age at diagnosis of GCA influenced the clinical presentation and risk of ischaemic complications, but did not affect the relapse rate during follow-up. LV-GCA occurred more frequently in younger patients and was an 